\title{
Coal miners' respiratory disease litigation
}

\author{
Robin Rudd
}

On 23 January 1998 Mr Justice Turner delivered his judgement in the longest and probably most expensive personal injury court case ever to take place in Britain, concerning respiratory disease in coal miners. The background to the trial was that many former miners in different parts of the country had initiated actions at common law against British Coal over a period of several years, some as long ago as 1989, claiming damages for occupational respiratory disease. This was disease other than pneumoconiosis for which there has for a long time been an agreed scheme of compensation by British Coal. Since 1992 there has been a "prescribed disease" of chronic bronchitis and emphysema for which Industrial Injuries Disablement Benefit is payable but, as with all types of occupational disease, the sufferer is entitled to pursue an action at common law against the employer(s) responsible for causing the disease in addition to claiming benefit from the state.

Solicitors representing different plaintiffs formed a group which acted collectively in the litigation and, at the request of legal representatives from both sides, the court decided that a test case should be heard which it was hoped would establish some general principles by which other cases could be dealt with subsequently. Eight lead cases were selected for the trial, some chosen by each side in the action, partly on grounds of being representative of some common situation and partly on grounds of being considered strong cases with which to illustrate their arguments. Six of the men were alive. Two had died before the case reached trial and actions continued on behalf of their estates.

The trial opened in October 1996 in London and then moved to Sheffield and later Cardiff to hear evidence from former miners about their past working conditions. In January 1997 the trial moved to London for expert evidence concerning causation-that is, the medical issues - and liability - that is, the extent to which the employers could be held to have failed to provide safe working conditions. Evidence was concluded in July 1997 and Counsel's closing submissions were made in September 1997. The transcript of the evidence occupied approximately 15000 pages and there were almost 50 lever arch files of medical reports and papers. A further 500 such files of papers were prepared for the court, although not all of their contents were introduced into evidence. The trial was assisted to a greater extent than any previous such case by information technology. A computer database was constructed which comprised the entire text of about 500 published medical papers, enabling all of them to be contained on a laptop computer and four compact discs. In the event this was of more assistance to the judge in reviewing the evidence and writing his judgement than it was in the course of the trial because in court it proved slower and less convenient to call the papers up on computer than to refer to the documents. Technology came into its own, however, with a transcription system called Livenote $\AA$. This allowed the stenographer's symbolic typing of the oral evidence to be immediately presented as ordinary text on numerous laptop computers around the court and a corrected, indexed, printed transcript of the day's evidence was usually available to the judge and both parties within 1-2 hours of the end of the day's hearing. This system enabled evidence to be taken much more quickly than would have been possible if it had been limited by the speed of the judge's pencil, as is commonly the case.

Some of the plaintiffs were funded by the South Wales branch of the National Association of Colliery Overmen, Deputies and Shotfirers (NACODS) and the others by Legal Aid. The defendant was British Coal but the body now responsible for the liabilities of this organisation is the Department of Trade and Industry. Since the defendant reimburses the costs of successful plaintiffs, the taxpayer will end up having funded nearly all the costs of both sides in this legal action. The costs of the litigation can only be guessed at present but are likely to run to several million pounds. It is interesting to speculate as to the administrative process and rationale underlying the decision on behalf of the defendant that the action should be defended to the last ditch rather than settled amicably, particularly as the position adopted by the defendant on medical causation was in effect a repudiation of the recommendations made to the government by its own advisory body, the Industrial Injuries Advisory Council.

The core issues on liability were the extent to which British Coal had taken steps to monitor and control dust exposure experienced by their miners. Despite producing a mass of dust data and detailed engineering reports, eventually the defendant did not seriously contest that the plaintiffs had been exposed to excessive quantities of dust and the argument reduced to the extent to which exposure should have been lower than it was. The judge concluded that there was "abundant evidence that officials interpreted their duties as requiring the production of coal first and the taking of precautions in respect of health second". The judge found that British Coal should have used more dust suppression, and in later years should have issued masks and urged men to use them.

A more serious contest arose from the medical issues. The plaintiff's case was that exposure to coal mine dust can cause chronic bronchitis-that is, sputum production according to the MRC definition-and potentially disabling loss of lung function as a result of emphysema and small airways disease in varying proportions. This was distinguished from loss of lung function associated with complicated pneumoconiosis - that is, progressive massive fibrosis-which was not present in the plaintiffs in this case. A secondary issue was the relative potency of coal mine dust and tobacco smoke in causing chronic bronchitis and emphysema, since most of the plaintiffs had been smokers.

The defendant accepted that dust causes chronic bronchitis but argued that this condition did not merit the award of any damages, the production and expulsion of mucus being a normal function of the body analogous to "opening of the pores of the skin on exercise". This was a surprising position as the Court of Appeal had decided in a previous case that a plaintiff is entitled to recover damages, albeit modest, for chronic bronchitis (Tanner $\mathrm{v}$ National Coal Board, 1991). In the Tanner case evidence given on behalf of the defendant by Dr Morgan to the effect that loss of lung function caused by dust exposure is minor was accepted and the defendant put forward the same argument in this case. 
The defendant's case was essentially the position which has for long been held by Morgan ${ }^{1}$ that dust causes chronic bronchitis which causes a small loss of lung function. This is accounted for by slight obstruction to airflow caused by the presence of mucus in the airways. Dust also causes focal dust emphysema which does not cause material impairment of lung function or disability. If disabling emphysema is present in a coal miner it is attributable to smoking. If he claims to be a lifelong non-smoker he may well be lying but, if he is not, either the diagnosis of emphysema is incorrect or his emphysema must be due to some unknown cause other than dust.

The plaintiffs relied to a considerable extent on the findings of the Pneumoconiosis Field Research (PFR), a programme of epidemiological research in British coal mines initiated in 1952 and continued over several decades. Initially the director of the PFR was the Chief Medical Officer to British Coal. In 1969 the Coal Board transferred responsibility for continuing the research, which it continued to fund, to the Institute of Occupational Medicine (IOM) in Edinburgh. The programme was set up to determine what environmental conditions should be maintained for miners not to be disabled by the dust they breathe. While the main focus in earlier years was the prevention of pneumoconiosis, as detected by radiographs, much information about respiratory symptoms and lung function was also collected. A detailed review of the findings from these and other studies by Professors Coggon and Newman-Taylor appears in this issue of Thorax. ${ }^{2}$

The defendant realised that the evidence from this research, if accepted, would inevitably lead to the conclusion that dust exposure causes loss of lung function which may be disabling. The defendant adopted a strategy of attempting to invalidate the entire programme of research and obtained and put into evidence the entire archives of papers relating to research on respiratory disease in coal miners from the IOM. These papers, which included minutes of meetings, correspondence between research workers, notes, working documents, raw data, and early drafts of manuscripts for publication, were subjected to detailed analysis. The defendant suggested that the answers to questionnaires about respiratory symptoms and smoking histories were unreliable, that spirometric measurements were flawed, and that dust levels had been estimated inaccurately, with the consequence that little reliance could be placed upon the conclusions drawn from the studies.

The plaintiffs countered with arguments that all epidemiological research is imperfect but that PFR studies are widely recognised to have been planned and executed as well as any of this type, and provide better evidence than is available in relation to most occupational respiratory hazards. Inaccuracies in the questionnaire and lung function data would not be likely to be differentially distributed according to heaviness of dust exposure, and inaccuracies in individual dust exposure estimates would not be likely to be differentially distributed in relation to smoking histories and lung function. Hence, deficiencies in the data would not be likely to lead to a spurious conclusion that there is an adverse effect of dust on lung function but would, if anything, tend to obscure such an effect since, in general, random errors in data make it more difficult to detect a real association. Evidence as to the validity of the PFR methods was given by Dr Jacobsen who had played an important part in much of the original work. Initially he was reluctant to become involved as he feared that to do so might be seen as compromising his impartiality, but he consented to assist the court when he appreciated the true nature of the attack on the PFR.
In an attempt to invalidate the conclusions of the PFR studies the defendant commissioned a complete re-analysis of the data set upon which the work of Marine and colleagues was based. ${ }^{3}$ This paper showed that high exposure to coal mine dust more than doubled the risk of disabling loss of lung function in both smokers and non-smokers and that smoking and high dust exposure had effects of comparable magnitude on lung function. The new analysis was carried out by the IOM in Edinburgh. The data were subjected to rigorous review and a variety of analyses. The conclusions reached by Marine et al were confirmed and strengthened to the extent that conclusions as to the effects of dust were shown not to be importantly affected by taking into account differences between pitssomething which had not been done in the original analysis.

It is not uncommon for parties to major personal injury litigation to commission further analyses of raw data in the hope of showing that the conclusions reached by original researchers were flawed. The unusual aspect of this case was that the original research which the defendant was seeking to undermine was work which had been commissioned by and performed on behalf of the defendant itself. Presumably the defendant should have had ample opportunity to express any proper concerns it might have had concerning the methods employed in the course of the research which had taken place over many years. In the event, the re-analysis confirmed the validity of the original conclusions and thereby strengthened the plaintiff's case. By the time closing submissions were made the defendant accepted that the attack on the PFR data had been repulsed, and stated "in general terms we do not seek to challenge the validity of the data upon which the studies are based", but it had not quite thrown in the towel and went on to say "although clearly the interpretation of the data is often a matter of controversy".

The re-analysis of the Marine data was only part of the defendant's case. A large body of medical literature was cited by both sides and numerous research papers were dissected in detail. The extent to which the lawyers were able to grasp and grapple with complex medical and statistical issues and identify the strengths and weaknesses of published studies was impressive. It was generally acknowledged that the analysis of the evidence undertaken by the court was more extensive and detailed than that undertaken by the Industrial Injuries Advisory Council (IIAC) in reaching its recommendations for the prescription of chronic bronchitis and emphysema.

Mr Justice Turner was not persuaded by the evidence given on behalf of the defendant concerning the relation between dust exposure and loss of lung function. He took the view that the defendant's case was argued from a preconceived position - that for so long and controversially espoused by Morgan - and ignored the import of much of the available evidence. Much consideration was given to the questions of susceptibility to smoking and to dust and the extent to which it is possible to attribute an observed loss of lung function in an individual to each agent. The judge considered that the preponderance of evidence supported the proposition that there is variability in the response to dust as well as to smoking and that the effect of dust is not a small effect evenly distributed across most of the population of miners, as contended on behalf of the defendant, but an effect which can lead to disabling disease in some men.

The judge's general findings were as follows:

(1) Coal mine dust (coal and stone) is a cause of centriacinar emphysema; 
(2) Such emphysema may, and usually does, lead to loss of ventilatory capacity most easily demonstrated by loss of $\mathrm{FEV}_{1}$;

(3) Confirmation that the causes and effects of tobacco smoke are as in findings (1) and (2) above;

(4) It is probable, but not certain, that there is a common causal pathway to both cigarette and mine dust induced emphysema which usually gives rise to breathlessness;

(5) Whether (4) is established or not, the effects are generally the same in that there is a spectrum of effect which is not clinically detectable in the majority of cases but in the minority does produce a range of effects from simple impairment, frank disability and, occasionally, death.

(6) In the individual smoker it is not possible to attribute the cause of breathlessness either to the one insult or the other; this is so whether or not there is a common pathway.

Having made these findings, the judge was faced with a three part apportionment exercise in awarding general damages - that is, recompense for pain and suffering. The first two parts related to apportionment as between the effects of dust and smoking and as between non-tortious or "innocent" and tortious or "guilty" dust exposure. Damages are awarded only for injury sustained as a result of tortious exposure - that is, that exposure which should have been avoided-and not that resulting from the unavoidable minimum dust exposure. This is a difficult area in law as well as from the point of view of medicine. A third apportionment was necessitated by the complexities of the law of limitation whereby damages cannot be recovered for injury which was sustained by June 1954; it was therefore also necessary to apportion injury as between that caused by dust exposure before and after 1954. The judge demonstrated the burden of his responsibilities when he echoed the feelings expressed by one of his learned colleagues, Mr Justice Brown, in his judgement in a previous case concerning the role of welding fumes in causing chronic airways disease: "During the long weeks of trial I have often wondered whether in truth this Court should be prepared to tread these paths of conjecture. . . But I have concluded that justice is too stern a master for that method of escape".

The judge decided that the uncertainties were too great for it to be realistic to attempt to calculate precise losses of $\mathrm{FEV}_{1}$ attributable to dust and smoking in each case, or to make assumptions about differential susceptibility to each hazard as he was eventually invited to do by the defendant towards the end of the trial when it had become clear that the defendant's basic premise that dust cannot cause disabling loss of lung function was not likely to be accepted. The apportionment as between dust and smoking which the judge adopted was loosely based upon a matrix suggested on behalf of the plaintiffs whereby high dust exposure, of the order of magnitude associated with a substantial risk of pneumoconiosis, is regarded, year for year, as equivalent to average smoking in causing loss of $\mathrm{FEV}_{1}$. The observed disablement in each individual plaintiff was apportioned accordingly with adjustments to take account of the heaviness of dust exposure and individual smoking habits. The former was determined by witness evidence and detailed analysis of colliery records and the latter were determined by witness evidence and detailed scrutiny of all available medical records. Damages were then awarded for that proportion of the impairment calculated to be due to the "guilty" exposure to dust after 1954 as a proportion of total dust exposure. The judge confirmed the decision in Tanner $\mathrm{v}$ British Coal that chronic bronchitis, in the absence of disabling loss of lung function, is a condition for which damages can be awarded.

Of the seven plaintiffs with chronic bronchitis and/or emphysema the judge awarded damages to six. These included five smokers and one non-smoker. Because of the apportionment exercise the sums awarded in general damages were modest, ranging from $£ 3200$ to $£ 12600$. Awards of special damages - that is, recompense for financial losses resulting from the injuries - were agreed between the parties at a later date. In relation to the seventh plaintiff the judge was not satisfied as to his reliability as a witness concerning either his respiratory symptoms or his smoking and decided that his case had not been proven. One of the eight plaintiffs differed from the others in having a primary diagnosis of asthma. This raised different issues from the main body of the trial concerning the extent to which exposure to the irritant effects of dust and nitrous fumes from shot firing could cause or exacerbate asthma. The plaintiffs' lawyers argued that this was a peripheral issue which should not be included in the test case, but the defendant's lawyers used their right to select some of the plaintiffs to include this case. The judge was not impressed with the reliability as a witness of the plaintiff and concluded that it had not been proven that his conditions of work had caused or materially exacerbated symptoms of his asthma.

The judgement in this case illustrates an advantage of common law as a means of compensating respiratory disease which can have both occupational and nonoccupational causes over the present system for the award of Industrial Injuries Disablement benefit. As demonstrated by Professor Seaton in this issue of Thorax, ${ }^{4}$ the present requirement of industrial injuries legislation defining prescribed diseases (Social Security Contributions and Benefits Act, 1992) to divide a continuum - that is, lung function impairment - into a dichotomy - that is, a condition either attributable or not attributable to occupationleads to an unsatisfactory situation whereby smokers are more likely than non-smokers to be awarded benefit for chronic bronchitis and emphysema and the theoretical possibility that a smoking miner with very little dust exposure could qualify for benefit. The law can take a more sophisticated approach whereby injury is apportioned between occupational and non-occupational factors and damages are awarded only for that part deemed to be occupational in origin. Theoretically, there is no reason why a similar approach could not be used for the award of Industrial Injuries Disablement benefit, although it would require a change in legislation and more detailed forensic enquiry by DSS Medical Boards - for example, scrutiny of past medical records - to try to minimise the impact of the inevitable tendency of some applicants to misrepresent their smoking habits.

Following the judgement there are likely to be thousands of other claims at common law from retired coal miners. If each of them has to go through the lengthy legal process, detailed assessments of medical histories, and engineering assessments of working conditions involved in the previously decided cases, the burden of work, the time taken to complete the exercise and the costs will be enormous. It is to be hoped that some sensible means of dealing with future cases can be worked out which will result in more money being spent on compensation for miners than on the costs of processing the claims.

There will be those who are tempted to suggest that the decision to award damages to these retired disabled coal miners was influenced by social or political considerations, as it was suggested that the decision of the IIAC to make chronic bronchitis and emphysema a prescribed disease was a political sop to assuage the anger arising from pit closures. ${ }^{5}$ Such a suggestion would be an injustice to the detailed consideration of the issues which took place in the course of this trial and to the careful deliberation of $\mathrm{Mr}$ Justice Turner; it should certainly not be made by anyone who has not read his judgement which runs to more than 
500 pages. For the faint hearted, a summary will be available on the Internet at http://www.open.gov.uk/lcd/ lcdhome.htm.

\section{London Chest Hospital, \\ Bonner Road, \\ London E2 97X, UK}

ROBIN RUDD

Witnesses who gave expert evidence on medical issues were as follows: Called by the plaintiffs: Dr B Armstrong, Dr G S Basran, Dr J Britton, Professor D Coggon, Dr P Howard, Dr M Jacobsen, Dr R M Rudd, Dr A J A Wightman.
Called by the defendant: Professor G Berry, Dr J A Dick, Dr K W C Morgan, Dr M G Pearson, Professor R A Stockley. Written evidence on behalf of the defendant was also provided by Professor T N Davis and Dr A Gibbs.

1 Morgan WKC. On dust, disability and death. Am Rev Respir Dis 1986;134:639-41.

2 Coggon D, Newman-Taylor A. Coal mining and chronic obstructive pulmonary disease: a review of the evidence. Thorax 1998;53:398-408.

3 Marine WM, Gurr D, Jacobsen M. Clinically important respiratory effects of dust exposure and smoking in British coal miners. Am Rev Respir Dis 1988;137:106-12.

4 Seaton A. The new prescription: industrial injuries benefits for smokers? Thorax 1998;53:335-6.

5 Morgan WKC. Coal mining, emphysema and compensation revisited. Occup Environ Med 1993;50:1051-3. 